\title{
Determinants of self-reported functional status (EPIC-26) in prostate cancer patients prior to treatment
}

\author{
Rebecca Roth ${ }^{1}$ (1) Sebastian Dieng ${ }^{2} \cdot$ Alisa Oesterle $^{2}$ - Günter Feick ${ }^{3}$ Günther Carl ${ }^{4} \cdot$ Andreas Hinkel $^{5}$. \\ Thomas Steiner $^{6} \cdot$ Björn Theodor Kaftan ${ }^{7} \cdot$ Frank Kunath $^{8} \cdot$ Boris Hadaschik $^{9} \cdot$ Simba-Joshua Oostdam $^{10}$. \\ Rein Jüri Palisaar ${ }^{11} \cdot$ Mateusz Koralewski $^{12} \cdot$ Burkhard Beyer $^{13}$ - Björn Haben ${ }^{14} \cdot$ Igor Tsaur $^{15}$. \\ Simone Wesselmann ${ }^{16} \cdot$ Christoph Kowalski ${ }^{16}$
}

Received: 13 May 2019 / Accepted: 19 January 2020 / Published online: 10 February 2020

(C) The Author(s) 2020

\begin{abstract}
Purpose The self-reported functional status (sr-FS) of prostate cancer (PCa) patients varies substantially between patients and health-care providers before treatment. Information about this issue is important for evaluating comparisons between health-care providers and to assist in treatment decision-making. There have been few reports on correlates of pretherapeutic sr-FS. The objective of the article, therefore, is to describe clinical and sociodemographic correlates of pretherapeutic sr-FS, based on a subset of the TrueNTH Global Registry, a prospective cohort study.

Methods A total of 3094 PCa patients receiving local treatment in 44 PCa centers in Germany were recruited between July 2016 and April 2018. Multilevel regression models were applied to predict five pretherapeutic sr-FS (EPIC-26) scores based on clinical characteristics (standard set suggested by the International Consortium for Health Outcomes Measurement), sociodemographic characteristics, and center characteristics.

Results Impaired pretherapeutic sr-FS tended to be associated with lower educational level and poorer disease characteristics-except for "urinary incontinence" which was only associated with age. Notably, age was a risk factor ("urinary incontinence," "urinary irritative/obstructive," "sexual") as well as a protective factor ("hormonal") for pretherapeutic sr-FS. Pretherapeutic sr-FS varies little across centers.

Conclusions Pretherapeutic sr-FS varies by clinical patient characteristics and age as well as by socioeconomic status. The findings point out the benefit of collecting and considering socioeconomic information in addition to clinical and demographic patient characteristics for treatment decision-making and fair comparisons between health-care providers.
\end{abstract}

Keywords Health-service research $\cdot$ Prostate neoplasms $\cdot$ Patient-reported outcome measures $\cdot$ Functional status $\cdot$ Case-mix adjustment $\cdot$ Multilevel analysis

\section{Introduction}

Improving the quality of health care requires information about patient outcomes. In addition to clinical outcomes such as survival, the importance of patient-reported outcome measures (PROMs) has increasingly been acknowledged in recent years [1]. PROMs are not only assessed in clinical

Electronic supplementary material The online version of this article (https://doi.org/10.1007/s00345-020-03097-z) contains supplementary material, which is available to authorized users.

Rebecca Roth

Rebecca.roth@uni-koeln.de

Extended author information available on the last page of the article trials [2], but also in routine care, for two major purposes: first, to assist in clinical decision-making and to monitor patients' health over time [3, 4]; second, for reasons of quality assurance and more specifically, to compare performance between health-care providers [5]. PROMs are particularly important in care for patients with prostate cancer (PCa) since the chances of long-term survival are very good [6], whereas impairment of functional status (FS) may be substantial [7]. Many initiatives such as the Michigan Urological Surgery Improvement Collaborative and the MartiniKlinik program have already implemented collection of PROM data in routine care for PCa patients $[8,9]$. However, such approaches are often isolated or involve programs that are limited to single locations or regions. 
In PCa patients, FS not only results from the treatment received but also varies substantially, long before treatment [10]. With the emergence of PROM assessment, information about this issue has become important for evaluating fair comparisons between health-care providers, identifying groups of patients who are at risk for impaired FS, and making treatment decisions accordingly. However, there have been few reports to date on correlates of pretherapeutic FS [11]. In particular, there is a lack of studies that go beyond clinical characteristics and include measures of socioeconomic status, although social determinants of health are high on the global public health agenda [12].

This paper is based on a multicenter sample of $\mathrm{PCa}$ patients receiving treatment from prostate cancer centers (PCCs) in Germany. The data were collected as part of the ongoing Prostate Cancer Outcomes (PCO) study [13]. The PCO study is part of the Movember-funded TrueNTH registry, which is collecting and harmonizing patient data in more than 15 countries worldwide [14]. The primary objective of the exploratory investigation presented in this article is the description of correlates, in terms of patient and center characteristics, with pretherapeutic selfreported FS (sr-FS).

\section{Patients and methods}

\section{Data collection}

Following approval of the study by the local ethics committee of the Medical Association of Berlin (Eth-12/16), PCCs certified by the German Cancer Society [15] were invited to participate in the PCO Study (DRKS00010774), an ongoing prospective, population-based cohort study [13]. Starting in July 2016, all PCa patients with a first diagnosis (any $\mathrm{T}$, any $\mathrm{N}, \mathrm{M} 0$ ) at one of the participating centers in Germany who were receiving local treatment as well as patients scheduled for active surveillance (AS) and watchful waiting (WW) were eligible for inclusion. Patients were excluded if they were unable to administer a questionnaire. After giving informed consent, participants were asked to answer a baseline (i.e., pretherapeutic) questionnaire within 3 months after diagnosis for patients scheduled for AS or WW afterwards or at least 3 months before local treatment. During the study, an annual follow-up questionnaire will be administered at least once. The analysis presented here is based on the pretherapeutic assessment. The pretherapeutic questionnaire includes items in accordance with the International Consortium for Health Outcomes Measurement (ICHOM) standard set for localized PCa [16], with three additional items (see "Measures"). The data were matched with clinical and treatment data.

\section{Measures}

The questionnaire includes the five Expanded Prostate Cancer Index Composite 26-item version (EPIC-26) domain scores on sr-FS calculated in accordance with the scoring instructions $[17,18]$. The domains for "urinary incontinence" and "urinary irritative/obstructive" consist of four items, for "hormonal" of five items, and for "bowel" and "sexual" of six items [17]. Lower scores (on a range of 0-100) indicate poorer function. Sociodemographic information was collected using items from the standard questionnaire used by the German pension insurance fund: highest school-leaving certificate (lower secondary school, intermediate secondary school, entrance certificate for a higher technical college/university of applied science, university entrance certificate, other, none); nationality (German with/or without another nationality, not German); health-insurance status (statutory, private). Patients with health insurance other than statutory or private $(n=11,0.4 \%)$ were excluded due to small patient numbers. Age (continuous) and disease and treatment information were documented by the hospital.

Risk classification at baseline (localized PCa with low/ intermediate/high risk, locally advanced $\mathrm{PCa}$, advanced $\mathrm{PCa}$; Online Resource 10) was coded according to the German clinical guideline [19, p. 60] combining prostatespecific antigen level, Gleason score, and clinical stage. Numbers of comorbidities at baseline were coded as 0 , 1 , or $\geq 2$ [16]. The type of first treatment initiated after questionnaire administration was grouped as radiotherapy (RT), radical prostatectomy (RPE), AS, and WW. Patients with other local treatments after questionnaire administration, e.g., radical cystoprostatectomy, and high-intensity focused ultrasound, were excluded $(n=14,0.5 \%)$ as well as patients who had received androgen deprivation therapy, AS, or WW before questionnaire administration $(n=196,6.3 \%)$.

PCC characteristics were urban status (small- to medium-sized town/large city/metropolitan city, i.e. $\leq 1$ $00,000 />100,000-1,000,000 />1,000,000$ inhabitants), the center's teaching status (university hospital/teaching hospital/nonteaching hospital), hospital ownership status (public/private/charitable), and recruitment rate (i.e., the rate of participating patients divided by the number of eligible patients at the respective PCC).

\section{Statistical analysis}

Descriptive analyses present means, standard deviation (SD), medians, interquartile ranges, and ranges for continuous variables, or numbers and percentages for categorical 
variables. In exploratory analyses, for each domain separately, associations with pretherapeutic sr-FS (outcome) were investigated using multivariable linear multilevel models to account for confounding and for the clustering of patients (level-1) in PCCs (level-2). A null model was used to calculate the intraclass correlation coefficient (ICC), i.e., the proportion of variance in pretherapeutic sr-FS explained by the variation between PCCs. Model 1 contains sociodemographic predictors only (independent variables), model 2 additionally comprises baseline disease information (independent variables), and model 3 also contains PCC characteristics (independent variables). Centers that recruited fewer than 10 patients were pooled, i.e., data were analyzed as if belonging to one common center. Values for PCC-level variables for pooled centers were calculated as weighted averages of center-specific variable values, where the center-specific relative sample size was used as the weighting. Missing data were not imputed. For categorical variables, missing categories were included in the multilevel models. The following sensitivity analyses were performed to investigate the robustness of the results of the multilevel analyses for model 3 with respect to a deviation from the assumption of normality of residuals: first, bootstrapping (10,000 samples); second, multilevel analyses for rankit-transformed scores (aiming to achieve normality); third, generalized multilevel analyses using penalized quasi-likelihood, assuming a gamma distribution of scores (not assuming normality). Further sensitivity analyses for model 3 were performed by excluding centers that did not document comorbidities, and with additional adjustment for the type of treatment to account for differences in recruitment according to the different specialists (urologists/radiotherapists) and treatment provided.

As this is an exploratory study, no correction for multiple testing was performed. $P$ values $<0.05$ were regarded as statistically significant. Statistical computations were carried out using the R program [20]. The lme4 package was used for multilevel analysis [21]. Generalized linear multilevel models were run using the MASS package [22].

\section{Results}

Data of 44 centers and 3094 patients who were recruited between July 1, 2016, and March 29, 2018, were collected. Table 1 presents descriptive analyses of the patients and centers that were included in multilevel analyses after exclusion of patients as reported above and those with missing information $(n=220(7 \%)$ patients excluded; Online Resource 1). The lowest pretherapeutic sr-FS was observed for the "sexual" domain (mean $\pm \mathrm{SD}=58.95 \pm 29.30$ ), the highest pretherapeutic sr-FS was noted for the "bowel" domain (mean $\pm \mathrm{SD}=95.96 \pm 9.56)$. The percentage of missing pretherapeutic sr-FS for individual domains ranged between $4.4 \%$ ("sexual") and $8.7 \%$ ("urinary irritative/ obstructive"). The percentage of missing values was low for predictor variables $(0-5 \%)$, except for the number of comorbidities $(21.6 \%)$, which is mainly attributable to 14 centers in which comorbidities were not documented. For multilevel analyses, two centers (10 patients) were pooled. One center (21 patients) was excluded from analyses of model 3 due to a missing recruitment rate.

The results of the multilevel analyses were consistent across models 1 (Online Resource 2), 2 (Online Resource 3), and 3 (Table 2). No uniform patterns emerged across the five EPIC-26 domains (Table 2); with regard to sociodemographic factors, older age was associated with poorer pretherapeutic functioning for "urinary incontinence", "urinary irritative/obstructive", and-most strongly-"sexual"-i.e., with each year of age, the pretherapeutic "sexual" sr-FS is reduced by 1.38 points. By contrast, older age was related to an improved pretherapeutic "hormonal" sr-FS. Higher educational levels were associated with better pretherapeutic sr-FS in the "hormonal" domain and more strongly in the "sexual" domain, e.g., sr-FS was 8.34 higher for patients with a university entrance certificate compared to patients with lower secondary school-leaving certificates. For the "irritative/obstructive" and "bowel" domains, no schoolleaving certificate versus a lower secondary school certificate was associated with significantly lower pretherapeutic sr-FS.

With regard to clinical predictors, comorbidities were associated with lower pretherapeutic sr-FS in the "bowel", "sexual", and "hormonal" domains. Most notably, in the "sexual" domain, patients with two or more comorbidities scored 8.80 points lower than patients without comorbidities. In addition, some higher risk classes, i.e., risk class "localized PCa with high risk" and higher, were associated with poorer pretherapeutic sr-FS in the "bowel", "hormonal" and most pronounced in the "urinary irritative/obstructive" domain; the sr-FS was reduced by 13.39 points for patients with advanced PCa versus localized PCa with low risk.

Variation in pretherapeutic sr-FS across centers was low [range of ICCs in the null models: $<0.001$ ("bowel") to 0.024 ("sexual"); Online Resource 4] and decreased further after controlling for patient-level variables (i.e., for model 1 and 2).

With regard to center characteristics (Table 2), in the "bowel" domain, higher recruitment was associated with higher pretherapeutic sr-FS and was also observed for large cities versus small- to medium-sized towns. By contrast, pretherapeutic sr-FS in the "bowel" domain was lower in PCCs of charitable versus public ownership and in university versus non-university teaching hospitals. A decreased pretherapeutic sr-FS was also observed in the "urinary irritative/ 
Table 1 Descriptive statistics for patient characteristics - pretherapeutic functional status and predictor variables

\begin{tabular}{|c|c|c|c|}
\hline Variable & Mean \pm SD & Median (IQR) & Range \\
\hline \multicolumn{4}{|l|}{ Pretherapeutic functional status } \\
\hline Urinary incontinence (missing: $6.3 \% ; n=193$ ) & $92.39 \pm 14.54$ & $100(91.75-100)$ & $0-100$ \\
\hline Urinary irritative/obstructive (missing: $8.7 \% ; n=269$ ) & $85.55 \pm 15.95$ & $87.5(75-100)$ & $0-100$ \\
\hline Bowel (missing: $8.3 \% ; n=257$ ) & $95.96 \pm 9.56$ & $100(95.83-100)$ & $29.17-100$ \\
\hline Sexual (missing: $4.4 \% ; n=135$ ) & $58.95 \pm 29.3$ & $62.5(33.4-87.5)$ & $0-100$ \\
\hline Hormonal (missing: $6.2 \% ;(n=192)$ & $90.05 \pm 14.49$ & $95(85-100)$ & $0-100$ \\
\hline \multicolumn{4}{|l|}{ Patient characteristics } \\
\hline \multicolumn{4}{|l|}{ Sociodemographic information } \\
\hline \multirow[t]{2}{*}{ Age (missing: $0 \% ; n=0$ ) } & $66 \pm 7$ & $66(61-72)$ & $39-85$ \\
\hline & $\%$ & $n$ & \\
\hline \multicolumn{4}{|l|}{ Nationality (missing: $4.7 \% ; n=145$ ) } \\
\hline German & 91.6 & 2632 & \\
\hline Other & 3.6 & 104 & \\
\hline \multicolumn{4}{|l|}{ Health insurance (missing: $4.7 \% ; n=146$ ) } \\
\hline Statutory & 73.6 & 2115 & \\
\hline Private & 21.6 & 620 & \\
\hline \multicolumn{4}{|l|}{ School-leaving qualification (missing: $5 \% ; n=154$ ) } \\
\hline Lower secondary school & 37.2 & 1069 & \\
\hline Intermediate secondary school & 23.5 & 675 & \\
\hline FHSR & 11.8 & 339 & \\
\hline University entrance certificate & 20.1 & 578 & \\
\hline Other & 1.6 & 45 & \\
\hline None & 0.7 & 20 & \\
\hline \multicolumn{4}{|l|}{ Disease information } \\
\hline \multicolumn{4}{|l|}{ Comorbidities (missing: $21.6 \% ; n=666$ ) } \\
\hline 0 & 49 & 1408 & \\
\hline 1 & 22.5 & 647 & \\
\hline$\geq 2$ & 7.3 & 210 & \\
\hline \multicolumn{4}{|l|}{ Risk class ${ }^{\text {a }}$ (missing: $0 \% ; n=0$ ) } \\
\hline High, localized & 32.2 & 924 & \\
\hline Intermediate, localized & 46.1 & 1325 & \\
\hline Low, localized & 15.9 & 457 & \\
\hline Locally advanced & 4.7 & 136 & \\
\hline Advanced & 1.1 & 32 & \\
\hline \multicolumn{4}{|l|}{ Treatment allocation } \\
\hline \multicolumn{4}{|c|}{ Treatment initiated after questionnaire administration(missing: $0 \% ; n=0$ ) } \\
\hline RPE & 93.1 & 2676 & \\
\hline RT & 5.5 & 159 & \\
\hline AS & 1.1 & 31 & \\
\hline WW & 0.3 & 8 & \\
\hline Center characteristics & Mean \pm SD & Median (IQR) & Range \\
\hline \multirow[t]{2}{*}{ Recruitment rate (missing: $0.7 \% ; n=21$ ) } & $50.92 \pm 17.08$ & $56(38-62)$ & $5-95$ \\
\hline & $\%$ & $\mathrm{n}$ & \\
\hline \multicolumn{4}{|l|}{ Ownership (missing: $0 \% ; n=0$ ) } \\
\hline Charitable & 3.0 & 86 & \\
\hline For profit & 51.5 & 1481 & \\
\hline Public & 45.5 & 1307 & \\
\hline
\end{tabular}


Table 1 (continued)

\begin{tabular}{lll}
\hline Center characteristics & Mean \pm SD & Median (IQR) \\
\hline Urban status (missing: $0 \% ; n=0)$ & & 992 \\
$\leq 100,000$ & 34.5 & 1710 \\
$>100,000-1,000,000$ & 59.5 & 172 \\
$>1,000,000$ & 6.0 & 117 \\
Teaching status (missing: 0\%; $n=0)$ & & 2293 \\
No & 4.1 & 464 \\
Yes, non-university & 79.8 & 16.1 \\
Yes, university & & 46 \\
\hline
\end{tabular}

${ }^{a}$ Risk class in accordance with the German clinical guideline [28]

$A S$ active surveillance, FHSR Fachhochschulreife, entrance certificate for a higher technical college/university of applied science, IQR interquartile range, $R P E$ radical prostatectomy, $R T$ radiotherapy, $S D$ standard deviation, $W W$ watchful waiting

obstructive" domain for nonteaching versus non-university teaching hospitals.

The results of the sensitivity analyses largely confirmed the results of the main analyses of model 3 (Online Resources 5-9). In the sensitivity analyses after adjustment for the type of treatment, associations were detected between treatment decision and pretherapeutic function; in comparison with treatment with RPE, RT was associated with poorer sr-FS in the "hormonal" domain, i.e., sr-FS was 3.18 points lower for patients treated with RT compared to RPE. AS was associated with poorer sr-FS in the "urinary incontinence" and "urinary irritative/obstructive" domains. WW was associated with poorer sr-FS in the "urinary incontinence" and "bowel" domains.

\section{Discussion}

Correlates of pretherapeutic sr-FS are rarely discussed in the literature. However, knowledge about such associations is of importance for clinicians to more easily identify patients at risk for impaired function and to consider this in treatment decision-making. This is especially true since sr-FS is not only associated with clinical characteristics and age - a matter of given for every provider-but also with socioeconomic status, as shown in this study. In addition, findings may sharpen practitioners understanding of why patient-specific information is needed to allow for fair comparisons between health-care providers. This paper provides such information for pretherapeutic sr-FS from a large multicenter population of PCa patients in Germany. Correlates of pretherapeutic sr-FS were sociodemographic and clinical patient characteristics: age was a risk factor for impaired sr-FS in the "urinary incontinence," "urinary irritative/obstructive," and "sexual" domains and a protective factor in the "hormonal" domain-a finding that corresponds to the results of a prospective cohort study in the United States
[23]. The latter association may, however, be a result of perception rather than a true protective effect of age, i.e., aging men during andropause may already have suffered from corresponding symptoms some time before $\mathrm{PCa}$ diagnosis and may, therefore, have adjusted to symptoms [24]. In clinical practice, when counseling patients, interpretation of the presented results may also benefit from the results of Laviana et al. who broke down the domain scores into functional outcomes to better interpret the domain scores [25]. In the present analyses, impaired pretherapeutic sr-FS correlated with lower educational level ("urinary irritative/obstructive," "bowel," "sexual," "hormonal"), comorbidities ("bowel," "sexual," "hormonal"; comparable results reported in [23]), and higher risk classes (i.e., risk classes "localized PCa with high risk" and higher; "urinary irritative/obstructive," "bowel", "hormonal"). Sensitivity analyses showed, i.a., that pretherapeutic sr-FS was lower for patients treated with RT compared to RPE in the "hormonal" domain, a finding corresponding to results of a study comparing external-beam RT with RPE [26]. However, our results must be interpreted with caution as they may reflect differential recruitment relative to treatment rather than differences between treatment groups. Furthermore, our study data do not allow for any conclusion on whether pretherapeutic sr-FS influences the choice of treatment. Many of our findings require further in-depth analysis-e.g., the large gradient relative to educational level in the sexual domain, which may in part be due to the patients' desire to report better than actual sexual ability.

The robustness of the results was demonstrated in sensitivity analyses. In addition, the data allow unbiased calculation of the recruitment rate for each center [13], making adjustment possible for potential methodological artifacts that are typically not addressed. However, some limitations of the study need to be highlighted: recruitment varied widely across centers and relative to (1) the type of treatment administered (RT underrepresented), (2) insurance 
Table 2 Results of linear multilevel analyses for self-reported pretherapeutic functional status (model 3)

$\begin{array}{lllll}\begin{array}{l}\text { Urinary incontinence } \\ (2679 \text { patients, } 42 \text { centers })\end{array} & \begin{array}{l}\text { Urinary irritative/obstructive } \\ (2612 \text { patients, } 42 \text { centers })\end{array} & \begin{array}{l}\text { Bowel (2617 patients, } 42 \\ \text { centers })\end{array} & \begin{array}{l}\text { Sexual }(2729 \text { patients, } 42 \\ \text { centers })\end{array} & \begin{array}{l}\text { Hormonal }(2678 \text { patients, } \\ 42 \text { centers })\end{array} \\ \text { Estimate }(95 \% \mathrm{CI}) ; p \text { value } & \text { Estimate }(95 \% \mathrm{CI}) ; p \text { value } & \begin{array}{l}\text { Estimate }(95 \% \mathrm{CI}) ; p \\ \text { value }\end{array} & \begin{array}{l}\text { Estimate }(95 \% \mathrm{CI}) ; p \\ \text { value }\end{array} & \begin{array}{l}\text { Estimate }(95 \% \mathrm{CI}) ; p \\ \text { value }\end{array}\end{array}$

\begin{tabular}{|c|c|c|c|c|c|}
\hline (Intercept) & 104.35 (98.68 to 110.02$)$ & 95.67 (89.34 to 101.99$)$ & 95.5 (91.83 to 99.16$)$ & $149.06(138.71$ to 159.4$)$ & $75.45(69.99$ to 80.92$)$ \\
\hline \multicolumn{6}{|l|}{ Patient characteristics } \\
\hline \multicolumn{6}{|c|}{ Sociodemographic information } \\
\hline Age & $\begin{array}{l}-0.19(-0.27 \text { to }-0.11) \\
<0.001 *\end{array}$ & $\begin{array}{l}-0.13(-0.21 \text { to }-0.04) \\
0.004 *\end{array}$ & $\begin{array}{l}0(-0.05 \text { to } 0.05) \\
0.905\end{array}$ & $\begin{array}{l}-1.38(-1.53 \text { to }-1.24) \\
<0.001 *\end{array}$ & $\begin{array}{l}0.25(0.17 \text { to } 0.32) \\
<0.001 *\end{array}$ \\
\hline \multicolumn{6}{|c|}{ Nationality (reference: German) } \\
\hline Other & $\begin{array}{l}-2.18(-5.30 \text { to } 0.94) \\
0.170\end{array}$ & $\begin{array}{l}-2.94 \text { ( }-6.37 \text { to } 0.49) \\
0.093\end{array}$ & $\begin{array}{l}0.13(-1.91 \text { to } 2.18) \\
0.898\end{array}$ & $\begin{array}{l}0.47(-5.30 \text { to } 6.24) \\
0.872\end{array}$ & $\begin{array}{l}0.47(-2.56 \text { to } 3.5) \\
0.760\end{array}$ \\
\hline \multicolumn{6}{|c|}{ Insurance (reference: statutory) } \\
\hline Private & $\begin{array}{l}1.18(-0.26 \text { to } 2.62) \\
0.109\end{array}$ & $\begin{array}{l}1.27(-0.33 \text { to } 2.86) \\
0.119\end{array}$ & $\begin{array}{l}0.72(-0.24 \text { to } 1.67) \\
0.140\end{array}$ & $\begin{array}{l}2.44(-0.21 \text { to } 5.08) \\
0.071\end{array}$ & $\begin{array}{l}1.28(-0.13 \text { to } 2.70) \\
0.076\end{array}$ \\
\hline \multicolumn{6}{|c|}{ School-leaving qualification (reference: lower secondary school) } \\
\hline $\begin{array}{l}\text { Intermediate sec- } \\
\text { ondary school }\end{array}$ & $\begin{array}{l}1.35(-0.13 \text { to } 2.84) \\
0.074\end{array}$ & $\begin{array}{l}0.69(-0.96 \text { to } 2.34) \\
0.411\end{array}$ & $\begin{array}{l}0.34(-0.65 \text { to } 1.33) \\
0.505\end{array}$ & $\begin{array}{l}3.45(0.75 \text { to } 6.16) \\
0.012 *\end{array}$ & $\begin{array}{l}2.16(0.69 \text { to } 3.63) \\
0.004 *\end{array}$ \\
\hline FHSR & $\begin{array}{l}0.94(-0.92 \text { to } 2.79) \\
0.323\end{array}$ & $\begin{array}{l}-0.26(-2.31 \text { to } 1.79) \\
0.803\end{array}$ & $\begin{array}{l}-0.77(-2.01 \text { to } 0.48) \\
0.226\end{array}$ & $\begin{array}{l}6.40(2.99 \text { to } 9.81) \\
<0.001 *\end{array}$ & $\begin{array}{l}-0.09(-1.94 \text { to } 1.76) \\
0.921\end{array}$ \\
\hline $\begin{array}{l}\text { University entrance } \\
\text { certificate }\end{array}$ & $\begin{array}{l}0.74(-0.89 \text { to } 2.37) \\
0.375\end{array}$ & $\begin{array}{l}0.18(-1.63 \text { to } 1.98) \\
0.849\end{array}$ & $\begin{array}{l}0.18(-0.91 \text { to } 1.27) \\
0.746\end{array}$ & $\begin{array}{l}8.34(5.34 \text { to } 11.34) \\
<0.001 *\end{array}$ & $\begin{array}{l}2.01(0.41 \text { to } 3.62) \\
0.014 *\end{array}$ \\
\hline Other & $\begin{array}{l}0.64(-3.93 \text { to } 5.21) \\
0.784\end{array}$ & $\begin{array}{l}-2.43(-7.48 \text { to } 2.61) \\
0.344\end{array}$ & $\begin{array}{l}0.95(-2.00 \text { to } 3.90) \\
0.529\end{array}$ & $\begin{array}{l}-1.45(-9.80 \text { to } 6.90) \\
0.733\end{array}$ & $\begin{array}{l}1.53(-2.95 \text { to } 6.00) \\
0.504\end{array}$ \\
\hline None & $\begin{array}{l}-0.58(-7.42 \text { to } 6.26) \\
0.869\end{array}$ & $\begin{array}{l}-10.46(-17.93 \text { to }-3.00) \\
0.006 *\end{array}$ & $\begin{array}{l}-4.70(-9.01 \text { to }-0.40) \\
0.032 *\end{array}$ & $\begin{array}{l}-7.85(-19.92 \text { to } 4.22) \\
0.202\end{array}$ & $\begin{array}{l}0.76(-5.86 \text { to } 7.39) \\
0.821\end{array}$ \\
\hline \multicolumn{6}{|l|}{ Disease information } \\
\hline \multicolumn{6}{|c|}{ Comorbidities (reference: 0 ) } \\
\hline 1 & $\begin{array}{l}0.34(-1.12 \text { to } 1.79) \\
0.652\end{array}$ & $\begin{array}{l}0.67(-0.96 \text { to } 2.31) \\
0.419\end{array}$ & $\begin{array}{l}-0.40(-1.34 \text { to } 0.55) \\
0.412\end{array}$ & $\begin{array}{l}-4.82(-7.50 \text { to }-2.15) \\
<0.001 *\end{array}$ & $\begin{array}{l}-2.16(-3.56 \text { to }-0.75) \\
0.003 *\end{array}$ \\
\hline$\geq 2$ & $\begin{array}{l}1.17(-1.08 \text { to } 3.42) \\
0.308\end{array}$ & $\begin{array}{l}-1.63(-4.14 \text { to } 0.87) \\
0.201\end{array}$ & $\begin{array}{l}-1.71(-3.19 \text { to }-0.23) \\
0.023 *\end{array}$ & $\begin{array}{l}-8.80(-12.96 \text { to }-4.64) \\
\quad<0.001 *\end{array}$ & $\begin{array}{l}-4.38(-6.58 \text { to }-2.17) \\
<0.001 *\end{array}$ \\
\hline \multicolumn{6}{|c|}{ 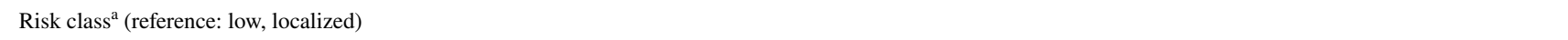 } \\
\hline High, localized & $\begin{array}{l}-0.44(-2.15 \text { to } 1.27) \\
0.616\end{array}$ & $\begin{array}{l}-2.12(-4.01 \text { to }-0.22) \\
0.029 *\end{array}$ & $\begin{array}{l}-1.33(-2.48 \text { to }-0.19) \\
0.023 *\end{array}$ & $\begin{array}{l}-0.89(-4.03 \text { to } 2.25) \\
0.578\end{array}$ & $\begin{array}{l}-1.97(-3.66 \text { to }-0.27) \\
0.023 *\end{array}$ \\
\hline $\begin{array}{l}\text { Intermediate, } \\
\text { localized }\end{array}$ & $\begin{array}{l}0.56(-1.06 \text { to } 2.18) \\
0.495\end{array}$ & $\begin{array}{l}-0.13(-1.93 \text { to } 1.67) \\
0.889\end{array}$ & $\begin{array}{l}-0.76(-1.85 \text { to } 0.32) \\
0.169\end{array}$ & $\begin{array}{l}1.85(-1.12 \text { to } 4.83) \\
0.222\end{array}$ & $\begin{array}{l}-0.37(-1.98 \text { to } 1.24) \\
0.654\end{array}$ \\
\hline Locally advanced & $\begin{array}{l}1.32(-1.61 \text { to } 4.25) \\
0.377\end{array}$ & $\begin{array}{l}-3.48(-6.71 \text { to }-0.24) \\
0.035 *\end{array}$ & $\begin{array}{l}-1.12(-3.05 \text { to } 0.82) \\
0.259\end{array}$ & $\begin{array}{l}-1.01(-6.31 \text { to } 4.29) \\
0.710\end{array}$ & $\begin{array}{l}-1.35(-4.26 \text { to } 1.57) \\
0.365\end{array}$ \\
\hline Advanced (N1) & $\begin{array}{l}-1.99(-7.37 \text { to } 3.38) \\
0.468\end{array}$ & $\begin{array}{l}-13.39(-19.36 \text { to }-7.41) \\
<0.001\end{array}$ & $\begin{array}{l}-5.32(-8.93 \text { to }-1.71) \\
0.004 *\end{array}$ & $\begin{array}{l}-8.05(-18.01 \text { to } 1.91) \\
0.113\end{array}$ & $\begin{array}{l}-0.98(-6.15 \text { to } 4.18) \\
0.709\end{array}$ \\
\hline \multicolumn{6}{|l|}{ Center characteristics } \\
\hline Recruitment rate & $\begin{array}{l}-1.12(-5.15 \text { to } 2.91) \\
0.586\end{array}$ & $\begin{array}{l}0.06(-4.69 \text { to } 4.80) \\
0.982\end{array}$ & $\begin{array}{l}2.60(0.20 \text { to } 5.01) \\
0.034 *\end{array}$ & $\begin{array}{l}-0.37(-7.52 \text { to } 6.77) \\
0.918\end{array}$ & $\begin{array}{l}-2.11(-5.64 \text { to } 1.42) \\
0.241\end{array}$ \\
\hline \multicolumn{6}{|c|}{ Ownership (reference: public) } \\
\hline Charitable & $\begin{array}{l}0.25(-3.98 \text { to } 4.48) \\
0.908\end{array}$ & $\begin{array}{l}-1.27(-6.17 \text { to } 3.63) \\
0.612\end{array}$ & $\begin{array}{l}-2.68(-5.19 \text { to }-0.17) \\
0.037 *\end{array}$ & $\begin{array}{l}-2.01(-9.43 \text { to } 5.41) \\
0.595\end{array}$ & $\begin{array}{l}-2.73(-6.44 \text { to } 0.98) \\
0.149\end{array}$ \\
\hline For profit & $\begin{array}{l}-0.17(-2.10 \text { to } 1.77) \\
0.865\end{array}$ & $\begin{array}{l}0.12(-2.17 \text { to } 2.40) \\
0.920\end{array}$ & $\begin{array}{l}-1.01(-2.15 \text { to } 0.13) \\
0.083\end{array}$ & $\begin{array}{l}-0.65(-4.05 \text { to } 2.75) \\
0.708\end{array}$ & $\begin{array}{l}-0.59(-2.27 \text { to } 1.09) \\
0.489\end{array}$ \\
\hline \multicolumn{6}{|c|}{ Urban status (reference: $\leq 100,000$ ) } \\
\hline $\begin{array}{r}>100,000- \\
1,000,000\end{array}$ & $\begin{array}{l}0.24(-1.67 \text { to } 2.15) \\
0.805\end{array}$ & $\begin{array}{l}-1.42(-3.69 \text { to } 0.84) \\
0.218\end{array}$ & $\begin{array}{l}1.14(0.02 \text { to } 2.25) \\
0.046 *\end{array}$ & $\begin{array}{l}-0.34(-3.69 \text { to } 3.00) \\
0.841\end{array}$ & $\begin{array}{l}1.50(-0.15 \text { to } 3.14) \\
0.075\end{array}$ \\
\hline$>1,000,000$ & $\begin{array}{l}-1.68(-5.73 \text { to } 2.37) \\
0.415\end{array}$ & $\begin{array}{l}-3.63(-8.31 \text { to } 1.06) \\
0.129\end{array}$ & $\begin{array}{l}0.79(-1.64 \text { to } 3.23) \\
0.524\end{array}$ & $\begin{array}{l}-0.01(-7.34 \text { to } 7.32) \\
0.998\end{array}$ & $\begin{array}{l}2.53(-1.17 \text { to } 6.23) \\
0.181\end{array}$ \\
\hline
\end{tabular}


Table 2 (continued)

\begin{tabular}{|c|c|c|c|c|}
\hline $\begin{array}{l}\text { Urinary incontinence } \\
\text { (2679 patients, } 42 \text { centers) }\end{array}$ & $\begin{array}{l}\text { Urinary irritative/obstructive } \\
\text { (2612 patients, } 42 \text { centers) }\end{array}$ & $\begin{array}{l}\text { Bowel (2617 patients, } 42 \\
\text { centers) }\end{array}$ & $\begin{array}{l}\text { Sexual (2729 patients, } 42 \\
\text { centers) }\end{array}$ & $\begin{array}{l}\text { Hormonal ( } 2678 \text { patients, } \\
42 \text { centers) }\end{array}$ \\
\hline Estimate $(95 \% \mathrm{CI}) ; p$ value & Estimate $(95 \% \mathrm{CI}) ; p$ value & $\begin{array}{l}\text { Estimate }(95 \% \mathrm{CI}) ; p \\
\text { value }\end{array}$ & $\begin{array}{l}\text { Estimate }(95 \% \mathrm{CI}) ; p \\
\text { value }\end{array}$ & $\begin{array}{l}\text { Estimate }(95 \% \mathrm{CI}) ; p \\
\text { value }\end{array}$ \\
\hline \multicolumn{5}{|l|}{ s, non-university) } \\
\hline $\begin{array}{l}0.40(-2.92 \text { to } 3.71) \\
0.815\end{array}$ & $\begin{array}{l}-4.05(-7.92 \text { to }-0.17) \\
0.041 *\end{array}$ & $\begin{array}{l}1.30(-0.73 \text { to } 3.32) \\
0.209\end{array}$ & $\begin{array}{l}-2.99(-8.85 \text { to } 2.88) ; \\
0.318\end{array}$ & $\begin{array}{l}-0.93 \text { ( }-3.89 \text { to } 2.02) \text {; } \\
0.536\end{array}$ \\
\hline $\begin{array}{l}-1.18 \text { ( }-3.78 \text { to } 1.41) \\
0.371\end{array}$ & $\begin{array}{l}0.39(-2.69 \text { to } 3.47) \\
0.805\end{array}$ & $\begin{array}{l}-1.55(-3.02 \text { to }-0.08) \\
0.038\end{array}$ & $\begin{array}{l}-1.18 \text { ( }-5.72 \text { to } 3.36) \\
0.610\end{array}$ & $\begin{array}{l}-0.93(-3.10 \text { to } 1.25) \text {; } \\
0.404\end{array}$ \\
\hline
\end{tabular}

FHSR, Fachhochschulreife, entrance certificate for a higher technical college/university of applied science

*Bold estimates, confidence intervals, and $p$ values indicate $p$ values $<0.05$

1. Multilevel model 3 accounts for the clustering of patients (level-1) in prostate cancer centers (level-2) with a random intercept. Fixed effects for sociodemographic predictors, disease information, and prostate cancer center characteristics are included

2. Patient numbers vary between the analyses of different domains due to different numbers of missing values for the respective scores

3. Results for the missing categories for categorical variables are not presented in this table

${ }^{\text {a}}$ Risk class in accordance with the German clinical guideline [19]

status (private insurance overrepresented), (3) school-leaving qualification (higher degrees overrepresented), and (4) age (young age overrepresented), potentially biasing the results [13]. Notably, since $16.8 \%$ of patients in the present study were classified as low-risk patients, the percentage of patients under AS (1.9\%) appears to be particularly low. It may be argued that the selective recruitment relative to treatment in the present study is at least to some extent attributable to the restriction to patients receiving in-patient care [27]. In the present investigation, however, sensitivity analyses with adjustment for treatment choice, which may account for the selective recruitment, yielded results comparable to the main results. In this study, the quality of documentation in relation to missing values was good for the predictor variables - with the exception of the number of comorbidities since not all centers documented comorbidities. However, sensitivity analyses demonstrated the robustness of the results when only centers that documented comorbidities were taken into account. In addition, current knowledge does not allow any conclusions to be drawn regarding the clinical significance of effects on pretherapeutic FS scores reported in this study. However, the magnitude of effects appeared to be large for some associations (i.e., indicating a difference in the respective sr-FS score of $>5$ points), suggesting that the corresponding predictors are clinically relevant [26]. On a positive note, information on education was collected and was shown to be of high importance for identifying patients with impaired pretherapeutic sr-FS, a finding that has been shown for clinical outcomes earlier [28]. In similar studies, unfortunately, data on socioeconomic status are often missing and are also not suggested by the ICHOM standard set.

Pretherapeutic sr-FS varies according to clinical patient characteristics and age but also with respect to socioeconomic status-as measured by educational status. This points out the benefit of collecting and considering socioeconomic information in addition to clinical and demographic patient characteristics for treatment decision-making and fair comparisons between health-care providers. Confirmation of the present findings in further well-powered studies would be desirable.

Acknowledgements Open Access funding provided by Projekt DEAL. The authors would like to thank the patients who participated in the study, as well as the prostate cancer center staff who recruited patients and worked continuously on delivering and improving care. We would also like to thank the five anonymous reviewers who contributed substantially to making the manuscript easier to understand. Funding was received from the Movember Foundation through Help for Prostate Cancer Patients, the collaborating partner of the Movember Foundation in Germany.

Author contributions RR: data analysis and manuscript writing/editing. SD: protocol/project development, data collection or management, manuscript writing/editing. AO: data analysis, data collection or management. GF: protocol/project development and manuscript writing/ editing. GC: protocol/project development and manuscript writing/ editing. AH: data collection or management and manuscript writing/ editing. TS: data collection or management, and manuscript writing/ editing. BTK: data collection or management and manuscript writing/ editing. FK: data collection or management, manuscript writing/editing. BHad: data collection or management, manuscript writing/editing. SJO: data collection or management and manuscript writing/editing. RJP: data collection or management, and manuscript writing/editing. MK: data collection or management, and manuscript writing/editing. BB: data collection or management, and manuscript writing/editing. BHab: data collection or management, and manuscript writing/editing. IT: data collection or management, and manuscript writing/editing. SW: protocol/project development and manuscript writing/editing. CK: protocol/project development and manuscript writing/editing.

Funding This study was funded by the Movember Foundation.

\section{Compliance with ethical standards}

Conflict of interest RR, GF, GC, AH, TS, BB, BHab, FK, SJO, MK, $\mathrm{RJP}$, and IT declare that they have no conflicts of interest. CK, SD, AO, 
and SW are employed by the two institutions in charge of the certification system. BTK receives consulting and lecturing honoraries from various companies that are not in conflict with the work presented here. A comprehensive list will be provided upon demand. BHad reports grants from German Cancer Aid, and German Research Foundation, personal fees and non-financial support from Astellas, Astra Zeneca, Bayer, BMS, Janssen, Lightpoint Medical, and Sanofi, and grants and personal fees from Uromed, all unconnected with the submitted study.

Ethical approval All procedures performed in studies involving human participants were conducted in accordance with the ethical standards of the Ethics Committee of the Medical Association of Berlin (Eth12/16) and in accordance with the 1964 Helsinki Declaration and later amendments.

Informed consent Informed consent was obtained from all individual participants included in the study.

Open Access This article is licensed under a Creative Commons Attribution 4.0 International License, which permits use, sharing, adaptation, distribution and reproduction in any medium or format, as long as you give appropriate credit to the original author(s) and the source, provide a link to the Creative Commons licence, and indicate if changes were made. The images or other third party material in this article are included in the article's Creative Commons licence, unless indicated otherwise in a credit line to the material. If material is not included in the article's Creative Commons licence and your intended use is not permitted by statutory regulation or exceeds the permitted use, you will need to obtain permission directly from the copyright holder. To view a copy of this licence, visit http://creativecommons.org/licenses/by/4.0/.

\section{References}

1. Resnick MJ, Barocas DA, Morgans AK, Phillips SE, Koyama T, Albertsen PC, Cooperberg MR, Goodman M, Greenfield S, Hamilton AS, Hoffman KE, Hoffman RM, Kaplan SH, McCollum D, Paddock LE, Stanford JL, Stroup AM, Wu XC, Penson DF (2015) The evolution of self-reported urinary and sexual dysfunction over the last two decades: implications for comparative effectiveness research. Eur Urol 67(6):1019-1025. https://doi.org/10.1016/j. eururo.2014.08.035

2. Calvert M, Blazeby J, Altman DG, Revicki DA, Moher D, Brundage MD (2013) Reporting of patient-reported outcomes in randomized trials: the CONSORT PRO extension. JAMA 309(8):814822. https://doi.org/10.1001/jama.2013.879

3. Klinkhammer-Schalke M, Koller M, Steinger B, Ehret C, Ernst B, Wyatt JC, Hofstadter F, Lorenz W, Regensburg Qo LSG (2012) Direct improvement of quality of life using a tailored quality of life diagnosis and therapy pathway: randomised trial in 200 women with breast cancer. Br J Cancer 106(5):826-838. https:// doi.org/10.1038/bjc.2012.4

4. Basch E, Deal AM, Kris MG, Scher HI, Hudis CA, Sabbatini P, Rogak L, Bennett AV, Dueck AC, Atkinson TM, Chou JF, Dulko D, Sit L, Barz A, Novotny P, Fruscione M, Sloan JA, Schrag D (2016) Symptom monitoring with patient-reported outcomes during routine cancer treatment: a randomized controlled trial. J Clin Oncol 34(6):557-565. https://doi.org/10.1200/JCO.2015.63.0830

5. Hartz A, He T, Strope S, Cutler DR, Andriole G, Dechet C (2013) Surgeon variation in patient quality of life after radical prostatectomy. J Urol 189(4):1295-1301. https://doi.org/10.1016/j. juro.2012.10.118
6. Allemani C, Matsuda T, Di Carlo V, Harewood R, Matz M, Niksic M, Bonaventure A, Valkov M, Johnson CJ, Esteve J, Ogunbiyi OJ, Azevedo ESG, Chen WQ, Eser S, Engholm G, Stiller CA, Monnereau A, Woods RR, Visser O, Lim GH, Aitken J, Weir HK, Coleman MP (2018) Global surveillance of trends in cancer survival 2000-14 (CONCORD-3): analysis of individual records for 37513025 patients diagnosed with one of 18 cancers from 322 population-based registries in 71 countries. Lancet (London, England) 391(10125):1023-1075. https://doi. org/10.1016/s0140-6736(17)33326-3

7. Zaider T, Manne S, Nelson C, Mulhall J, Kissane D (2012) Loss of masculine identity, marital affection, and sexual bother in men with localized prostate cancer. J Sex Mede 9(10):27242732. https://doi.org/10.1111/j.1743-6109.2012.02897.x

8. Lucas SM, Kim TK, Ghani KR, Miller DC, Linsell S, Starr J, Peabody JO, Hurley P, Montie J, Cher ML (2017) Establishment of a web-based system for collection of patient-reported outcomes after radical prostatectomy in a statewide quality improvement collaborative. Urology 107:96-102. https://doi. org/10.1016/j.urology.2017.04.058

9. Beyer B, Mandel P, Michl U, Pompe RS, Veleva V, Steuber T, Huland H, Graefen M, Tilki D (2016) Oncological, functional and perioperative outcomes in transplant patients after radical prostatectomy. World J Urol 34(8):1101-1105. https://doi. org/10.1007/s00345-015-1758-2

10. Jacobs BL, Lopa SH, Yabes JG, Nelson JB, Barnato AE, Degenholtz HB (2016) Association of functional status and treatment choice among older men with prostate cancer in the Medicare Advantage population. Cancer 122(20):3199-3206. https://doi. org/10.1002/cncr.30184

11. Storås AH, Sanda MG, Ferrer M, Loge JH, Dahl AA, Steinsvik EAS, Guedea F, Cvancarova M, Fosså SD (2014) Localized prostate cancer in Norway, the United States, and Spain: between-country differences of variables before treatment among patients eligible for curative treatment. Clin Genitourin Cancer 12(4):e117-e125. https://doi.org/10.1016/j. clgc.2013.12.007

12. Marmot M (2005) Social determinants of health inequalities. Lancet 365(9464):1099-1104. https://doi.org/10.1016/s0140 -6736(05)74234-3

13. Kowalski C, Hein R, Carl G, Feick G, Oesterle A, Hinkel A, Steiner T, Brock M, Kaftan B, Borowitz R, Zantl N, Heidenreich A, Neisius A, Darr C, Bolenz C, Beyer B, Pfitzenmaier J, Brehmer B, Fichtner J, Haben B, Wesselmann S, Dieng S (submitted) Implementing a multicenter paper-based and web-based system for collecting patient-reported outcome measures in patients undergoing local treatment for prostate cancer: design and progress report.

14. Evans SM, Millar JL, Moore CM, Lewis JD, Huland H, Sampurno F, Connor SE, Villanti P, Litwin MS (2017) Cohort profile: the TrueNTH Global Registry-an international registry to monitor and improve localised prostate cancer health outcomes. BMJ Open 7(11):e017006. https://doi.org/10.1136/bmjopen-2017-017006

15. Kowalski C, Ferencz J, Albers P, Fichtner J, Wiegel T, Feick G, Wesselmann S (2016) Quality assessment in prostate cancer centers certified by the German Cancer Society. World J Urol 34(5):665-672. https://doi.org/10.1007/s00345-015-1688-z

16. Martin NE, Massey L, Stowell C, Bangma C, Briganti A, BillAxelson A, Blute M, Catto J, Chen RC, D'Amico AV, Feick G, Fitzpatrick JM, Frank SJ, Froehner M, Frydenberg M, Glaser A, Graefen M, Hamstra D, Kibel A, Mendenhall N, Moretti K, Ramon J, Roos I, Sandler H, Sullivan FJ, Swanson D, Tewari A, Vickers A, Wiegel T, Huland H (2015) Defining a standard set of patient-centered outcomes for men with localized prostate cancer. Eur Urol 67(3):460-467. https://doi.org/10.1016/j.eurur o.2014.08.075 
17. Sibert NT, Dieng S, Oesterle A, Feick G, Carl G, Steiner T, Minner J, Roghmann F, Kaftan B, Zengerling F, Hinkel A, Beyer B, Heidenreich A, Harke N, Brehmer B, Pfitzenmaier J, Fichtner J, Neisius A, Hammerer P, Wesselmann S, Kowalski C (2019) Psychometric validation of the German version of the EPIC-26 questionnaire for patients with localized and locally advanced prostate cancer. World J Urol. https://doi.org/10.1007/s00345-019-02949 $-7$

18. Sanda MG, Wei JT, Litwin MS (2002) Scoring instructions for the expanded prostate cancer index composite schort form (EPIC-26). The Universityy of Michigan, Ann Arbor

19. Leitlinienprogramm Onkologie (Deutsche Krebsgesellschaft DK, AWMF) (2018) [Interdisziplinäre Leitlinie der Qualität S3 zur Früherkennung, Diagnose und Therapie der verschiedenen Stadien des Prostatakarzinoms, Langversion 5.0].

20. Core Team R (2017) R: a language and environment for statistical computing. R Foundation for Statistical Computing, Vienna

21. Bates D, Mächler M, Bolker B, Walker S (2015) Fitting linear mixed-effects models using lme4. J Stat Softw. https://doi. org/10.18637/jss.v067.i01

22. Venables WN, Ripley BD (2002) Modern applied statistics with S, 4th edn. Springer, New York

23. Resnick MJ, Barocas DA, Morgans AK, Phillips SE, Chen VW, Cooperberg MR, Goodman M, Greenfield S, Hamilton AS, Hoffman KE, Kaplan SH, Paddock LE, Stroup AM, Wu XC, Koyama T, Penson DF (2014) Contemporary prevalence of pretreatment urinary, sexual, hormonal, and bowel dysfunction: defining the population at risk for harms of prostate cancer treatment. Cancer 120(8):1263-1271. https://doi.org/10.1002/cncr.28563
24. Rezaei N, Azadi A, Pakzad R (2018) Prevalence of andropause among Iranian men and its relationship with quality of life. Aging Male. https://doi.org/10.1080/13685538.2018.1490951

25. Laviana AA, Hernandez A, Huang LC, Zhao Z, Koyama T, Conwill R, Hoffman K, Feurer ID, Goodman M, Hamilton AS, Wu XC, Paddock LE, Stroup A, Cooperberg MR, Hashibe M, O'Neil BB, Kaplan SH, Greenfield S, Penson DF, Barocas DA (2019) Interpretation of Domain Scores on the EPIC: How Does the Domain Score Translate into Functional Outcomes? The Journal of urology:101097ju0000000000000392. doi:10.1097/ ju.0000000000000392

26. Barocas DA, Alvarez J, Resnick MJ et al (2017) Association between radiation therapy, surgery, or observation for localized prostate cancer and patient-reported outcomes after 3 years. JAMA 317(11):1126-1140. https://doi.org/10.1001/ jama.2017.1704

27. Herden J, Ansmann L, Ernstmann N, Schnell D, Weissbac L (2016) The treatment of localized prostate cancer in everyday practice in Germany. Dtsch Arztebl Int 113(19):329-336. https:// doi.org/10.3238/arztebl.2016.0329

28. Klein J, Ovd K (2015) Socioeconomic inequalities in prostate cancer survival: a review of the evidence and explanatory factors. Soc Sci Med. https://doi.org/10.1016/j.socscimed.2015.07.006

Publisher's Note Springer Nature remains neutral with regard to jurisdictional claims in published maps and institutional affiliations.

\section{Affiliations}

\section{Rebecca Roth ${ }^{1}$ - Sebastian Dieng ${ }^{2} \cdot$ Alisa Oesterle $^{2}$. Günter Feick ${ }^{3}$. Günther Carl ${ }^{4} \cdot$ Andreas Hinkel $^{5}$. Thomas Steiner $^{6} \cdot$ Björn Theodor Kaftan ${ }^{7} \cdot$ Frank Kunath $^{8} \cdot$ Boris Hadaschik $^{9} \cdot$ Simba-Joshua Oostdam $^{10}$. Rein Jüri Palisaar ${ }^{11} \cdot$ Mateusz Koralewski ${ }^{12}$. Burkhard Beyer ${ }^{13}$ (D) Björn Haben ${ }^{14} \cdot$ Igor Tsaur $^{15}$. Simone Wesselmann ${ }^{16} \cdot$ Christoph Kowalski $^{16}$}

Sebastian Dieng

s.dieng@onkozert.de

Alisa Oesterle

a.oesterle@onkozert.de

Günter Feick

g-feick@gmx.de

Günther Carl

guenther.carl@fhbp.de

Andreas Hinkel

andreas.hinkel@franziskus.de

Thomas Steiner

thomas.steiner@helios-gesundheit.de

Björn Theodor Kaftan

Bjoern.Kaftan@klinikum-lueneburg.de

Frank Kunath

frank.kunath@uk-erlangen.de

Boris Hadaschik

boris.hadaschik@uk-essen.de

Simba-Joshua Oostdam

simba.oostdam@gmail.com
Rein Jüri Palisaar

rein-jueri.palisaar@elisabethgruppe.de

Mateusz Koralewski

m.koralewski@bk-trier.de

Burkhard Beyer

b.beyer@uke.de

Björn Haben

haben@marien-kh-gmbh.de

Igor Tsaur

igor.tsaur@unimedizin-mainz.de

Simone Wesselmann

wesselmann@krebsgesellschaft.de

Christoph Kowalski

kowalski@krebsgesellschaft.de

Institute of Medical Statistics and Computational Biology (IMSB), Medical Faculty, University of Cologne, Kerpener Straße 62, 50937 Cologne, Germany

2 OnkoZert, Gartenstraße 24, 89231 Neu-Ulm, Germany 
3 Federal Association of German Prostate Cancer Patient Support Groups, Thomas-Mann-Str. 40, 5311 Bonn, Germany

4 Help for Prostate Cancer Patients (Förderverein Hilfe Bei Prostatakrebs e.V., FHbP), Louise Schroeder Ring 2, 25436 Tornesch, Germany

5 Franziskus Hospital, Kiskerstraße 26, 33615 Bielefeld, Germany

6 Helios Klinikum Erfurt, Nordhäuser Straße 74, 99089 Erfurt, Germany

7 Städtisches Klinikum Lüneburg, Bögelstraße 1, 21339 Lüneburg, Germany

8 Department of Urology and Pediatric Urology, University Hospital Erlangen, FAU Erlangen-Nürnberg, Krankenhausstraße 12, 91052 Erlangen, Germany

$9 \quad$ Klinik und Poliklinik für Urologie, Kinderurologie und Uroonkologie, Universitätsklinikum Essen (AöR), Hufelandstraße 55, 45147 Essen, Germany
10 Vinzenz-Krankenhaus Hannover, Lange-Feld-Str. 31, 30559 Hannover, Germany

11 Urologische Klinik, Marien Hospital Herne, Universitätsklinikum der Ruhr-Universität Bochum, Mitten in der ST. ELISABETH GRUPPE GmbH, Katholische Kliniken Rhein-Ruhr, Widumer Str. 8, Herne 44627, Germany

12 Urologie, Krankenhaus der Barmherzigen Brüder Trier, Nordallee 1, 54292 Trier, Germany

13 Martini-Klinik Prostate Cancer Center Hamburg, Martinistraße 52, 20246 Hamburg, Germany

14 St. Marien Hospital Ahaus, Wüllener Str. 101, 48683 Ahaus, Germany

15 Klinik und Poliklinik für Urologie und Kinderurologie, Universitätsmedizin der Johannes Gutenberg-Universität Mainz, Langenbeckstraße 1, 55131 Mainz, Germany

16 German Cancer Society, Kuno-Fischer-Straße 8, 14057 Berlin, Germany 